\title{
Masculinidades y feminidades en preadolescentes residentes en contextos rurales de Castilla-La Mancha
}

\author{
Masculinities and Feminities in Preadolescents Residents \\ in Rural Contexts of Castilla-La Mancha
}

Gema Jiménez Tostón y Francisco Javier Aroca Cifuentes ${ }^{1}$

\section{Resumen}

Este artículo presenta los principales resultados obtenidos del análisis cuantitativo exploratorio perteneciente a la investigación Las fronteras de la identidad de género: masculinidades y feminidades en contextos de interacción escolar. Se analizan 236 cuestionarios aplicados a preadolescentes de entornos educativos, de entre 11-16 años, residentes en poblaciones rurales de la provincia de Albacete. El cuestionario indaga en algunos de los diferentes aspectos que contribuyen al proceso de adquisición y expresión de la identidad de género de estos jóvenes, constituyendo agentes socializadores de primer orden.

Los resultados del estudio indican que, a pesar de prevalecer discursos igualitarios en la sociedad, sigue predominando en las personas adolescentes de estos entornos una visión y una expresión de género estereotipada de lo que supone ser hombre o mujer. Por otro lado, determinados contenidos audiovisuales que gran parte de los y las adolescentes consumen pueden influir tanto en las relaciones entre distintos géneros como en la carencia de un espíritu crítico, ya que dichos contenidos no son apropiados para estas edades y muestran unos modelos de hombres y mujeres estereotipados.

\section{Palabras clave}

Identidades de género, educación secundaria, preadolescentes, feminidad, masculinidad.

\section{Abstract}

This article presents the main results obtained in an exploratory quantitative analysis belonging to the investigation The frontiers of gender identity: masculinities and femininities in contexts of school interaction. We analyze 236 questionnaires applied to pre-adolescents in educational settings, between 11 and 16 years old, residents of rural towns in the province of Albacete. The questionnaire explores some of the different aspects that contribute to the process of acquisition and expression of the gender identity of these young people, constituting socializing agents of the first order.

The results of the study indicate that, despite prevailing egalitarian discourses in society, adolescents in these environments still predominate in a stereotyped vision and gender expression of what it means to be a man or a woman. On the other hand, certain audiovisual content that many of the adolescents consume can influence both the relationships between different genres and the lack of a critical spirit, since these contents are not appropriate for these ages and show models of men and women stereotyped.

\section{Keywords}

Gender identities, secondary education, preadolescents, femininity, masculinity. 


\section{Introducción}

Comprender sociológicamente cómo se construye la identidad de género y qué elementos influyen o condicionan este proceso en el ámbito escolar nos lleva directamente a indagar en el proceso de socialización, que sabemos se manifiesta desde una socialización diferencial de género, con características propias cuando pensamos en la etapa de la adolescencia. Es en la multidimensionalidad, desde un punto de vista sociológico, donde ponemos el foco en esta investigación, teniendo en cuenta sobre todo aspectos culturales y sociales que conforman las identidades de género de las y los adolescentes en nuestras sociedades actuales. Para ello, partiendo de la socialización diferencial de género como paradigma teórico, nos centraremos en aspectos que nos parecen cruciales, y que son fundamentales en la actualidad como agentes socializadores, como son los medios de comunicación.

En primer lugar, este artículo analiza, desde un punto de vista teórico, el proceso de socialización diferencial de género y los principales agentes socializadores que tienen mayor influencia en nuestra sociedad. Después, mostraremos los resultados más relevantes de la investigación, comenzando por el grado de sexismo del alumnado en relación, concretamente, con la influencia de la masculinidad hegemónica en los chicos. Seguidamente mostraremos, desde un punto de vista comparado, las expectativas que chicos y chicas tienen en relación con su futuro, y analizaremos el consumo de medios (televisión y redes sociales) y su influencia en la construcción de las identidades de género. Describiremos también las marcadas diferencias en los usos del tiempo libre entre chicos y chicas. El análisis de los resultados concluye con una aproximación a los referentes que tienen unos y otras, teniendo en cuenta las personas que admiran, relacionándolos con la influencia de los diferentes agentes de socialización. Finalmente, realizaremos una reflexión sobre la estrategia que los centros educativos pueden adoptar para contrarrestar o potenciar el influjo de determinados medios o agentes.

\section{Marco teórico}

\subsection{La socialización diferencial de género}

La socialización puede definirse como el mecanismo por el que se incorpora la persona individual a lo social. Es el proceso mediante el cual las personas individuales aprenden e interiorizan las formas normales de vida de una comunidad (Taberner, 2009: 61). Por su parte, el género se define sociológicamente como una categoría relacional, marcada por agencias o dimensiones que se muestran complejas y relacionadas entre sí. Así, se trataría de identificar y analizar «las objetivaciones de los procesos (y significados) subjetivos por medio de los cuales se construye el mundo intersubjetivo del sentido común» (Berger y Luckmann, 2003: 35). El ser humano es un ser social influido por el entorno, pero la forma concreta dentro de la cual se moldea la humanidad está determinada por las formaciones socioculturales. «Si bien es posible afirmar que el hombre posee una naturaleza, es más significativo decir que el hombre construye su propia naturaleza o, más sencillamente, que el hombre se produce a sí mismo» (Berger y Luckmann, 2003: 67)². Esta producción no es individual, sino social. Pese al lenguaje claramente sexista de estos autores, la teoría de la construcción social de la persona sigue siendo válida.

Para Berger y Luckmann, la socialización siempre se realiza en el contexto de una estructura social específica (2003: 202). Y en relación con la socialización de género:

2 Entendemos hombre como sinónimo de ser humano, pese a que en la obra de estos autores encontramos fases como «Sé que las “charlas de mujeres" no me atañen como hombre» (Berger y Luckmann, 2003: 62). 
"Las versiones masculina y femenina de la realidad se reconocen socialmente y este reconocimiento también se transmite en la socialización primaria. Asi pues, hay una supremacia pre-definida de la versión masculina para el niño varón y de la versión femenina para la mujer. El niño conocerá la versión que pertenece al otro sexo con el alcance que le han mediatizado los otros significantes del sexo opuesto, pero no se identificará con esa versión »(2003: 207).

Además, la identidad individual se crea y recrea a partir de procesos sociales:

"La identidad constituye, por supuesto, un elemento clave de la realidad subjetiva y en cuanto tal, se halla en una relación dialéctica con la sociedad. La identidad se forma por procesos sociales. Una vez. que cristaliza, es mantenida, modificada o aun reformada por las relaciones sociales. Los procesos sociales involucrados, tanto en la formación como en el mantenimiento de la identidad, se determinan por la estructura social» (Berger y Luckmann, 2003: 214).

Es a partir de esos condicionantes sociales de género como se configuran las identidades individuales. Así, el género se define sociológicamente como una «categoría relacional» y hay que tener en cuenta esa dimensión, además de otras básicas que definen la identidad de género: subjetiva, social, ética o moral. Analizar hasta qué punto influyen las identidades de género hegemónicas (Ruiz, 2014) es una de las finalidades de nuestra investigación.

La teoría de la construcción social del género parte de la diferente educación y socialización que se proporciona a hombres y a mujeres considerando, sobre todo, la infancia, las relaciones con padres y madres y, en general, la cultura en la que las personas estamos inmersas desde que nacemos y que nos condiciona durante toda la vida. Desde el nacimiento o, más bien, desde que determinadas pruebas médicas contribuyen a la asignación del sexo del bebé que todavía no ha nacido, comienza la tipificación de género. Es desde ese momento cuando los mandatos de género comienzan a condicionar a las personas, considerándolos tradiciones que apenas son cuestionadas. Un ejemplo de ello es la práctica casi universal -por lo menos en nuestro entorno- de agujerear las orejas a las recién nacidas con el fin de diferenciarlas de los bebés niños, además de «adornarlas» ya desde el nacimiento, porque son del sexo femenino. Según De Miguel (2015: 57-58) en nuestras sociedades formalmente igualitarias la desigualdad se inscribe en los propios cuerpos de las mujeres.

El proceso de adquisición de la identidad de género se realiza, entre otros factores, a través de la socialización diferencial, proceso que no solamente se construye en la infancia, puesto que es permanente y dinámico. Este proceso proporciona diferentes papeles a niños y niñas por razón del sexo de nacimiento, inscribiendo a los primeros en un mundo masculino y a las segundas en un mundo femenino. Las expectativas, lo que se espera de unos y otras, son diferentes, y están condicionadas en función del sexo.

Desde El segundo sexo de Simone de Beauvoir (1998), el binomio sexo-género nos ha ayudado a obtener respuestas fundamentadas sobre cómo la cultura nos condiciona más allá de la biología. En definitiva, cómo el género es una construcción social. Por un lado, si hablamos de sexo, podríamos pensar que se trata de características sexuales que se tienen desde el nacimiento y que son invariables. Hoy se puede poner esto en duda, a partir de la observación de la transexualidad/transgénero y de la intersexualidad. Así, el análisis identitario adquiere nuevas dimensiones que amplían y enriquecen la comprensión de la diversidad sexual y de género de las sociedades. Por otro lado, para Subirats y Tomé (2007), si hablamos de género, 
«hablamos de patrones de comportamiento que las sociedades atribuyen a los hombres o a las mujeres, y que presuponen un conjunto de formas de actuar que incluyen, también, un determinado tipo de deseo y comportamiento sexual para cada género. (...) Los géneros constituyen sistemas de identidades y comportamientos que, al prescribir lo que deben hacer los individuos (...), introducen una fuerte limitación en sus posibilidades de desarrollo bumano y les fuerzan a adaptarse a patrones que no siempre corresponden a sus capacidades y deseos». (21 y 23).

Así, los modelos de género son prescriptivos: son modelos sociales existentes a priori, que la sociedad impone a niños y niñas y les exige que se comporten de acuerdo con esos modelos (Subirats y Tomé, 2007: 30). Sin embargo, no hay una esencia femenina ni una esencia masculina, una manera única de ser mujer y de ser hombre, sino mil y una maneras diversas y plurales de ser mujeres y hombres. Ni todas las mujeres son iguales ni todos los hombres son iguales (Lomas, 2003). Por tanto, el concepto género definiría los estereotipos, los roles, las expectativas, los valores, que la sociedad impone desde la socialización y la educación a las personas, según se las considere hombres o mujeres desde un punto de vista biológico. «Las expectativas sobre los géneros son diferentes. Así, se espera que los niños sean competitivos, creativos, agresivos y un poco rebeldes; mientras que las niñas sean ordenadas, poco ambiciosas, pacíficas y pasivas. Cuando un individuo se desvía del comportamiento esperado el profesorado acostumbra a valorarlo negativamente» (Fernández, 2003: 372).

El proceso de socialización diferencial genera unas expectativas diferentes a (y hacia) niños y a niñas, a hombres y a mujeres. El estudio de las expectativas es fundamental a la hora de abordar esta investigación, puesto que éstas son generadas desde un punto de vista social -lo que se espera de nosotros y nosotras- y desde un punto de vista individual -lo que esperamos de nosotras y nosotros mismos-. El efecto Pigmalión o profecía autocumplida, unido al género como condicionante, tiene consecuencias en el proceso educativo fuera y dentro del aula. Las expectativas sociales son más rígidas y están limitadas por los estereotipos de género, que propician a su vez una uniformidad de género. Mientras que las expectativas individuales fluyen, van cambiando, se van adaptando, y es aquí donde puede aparecer la disidencia, diferenciándose de lo que se espera de nosotros y nosotras por pertenecer a uno u otro sexo. Por tanto, los objetivos de la socialización diferencial son homogeneizar y diferenciar al mismo tiempo (Rocha, 2009).

\subsection{Los agentes de la socialización diferencial}

Desde un punto de vista sociológico, identificamos los agentes de socialización tradicionales, que son la familia, la escuela, el grupo de iguales y los medios de comunicación. La socialización primaria es la llevada a cabo durante la infancia y supone la interiorización temprana de componentes afectivos, normativos y cognitivos, que el sujeto asume como un orden natural de las cosas que se le impone (Berger y Luckman, 2003: 162-172). Por su parte, la socialización secundaria es la que se recibe posteriormente a la niñez; es aquí cuando se interiorizan los roles sociales.

Los agentes de socialización tradicionales se están viendo envueltos en una serie de cambios importantes, ya que se están difuminando los límites de sus funciones y la importancia de cada agente a lo largo de la vida. Así, un agente de socialización secundario como son los medios de comunicación, hoy en día representa un papel primario, puesto que prácticamente desde el nacimiento las personas estamos influidas enormemente por las pantallas, en la medida en que las nuevas generaciones tienen más dispositivos a su alcance y cada vez a edades más tempranas. En nuestras sociedades tecnológi- 
camente avanzadas y complejas, los papeles que desempeñan los diferentes agentes de socialización han ido cambiando, a medida que los estilos educativos parentales, los tipos de familia y otros cambios sociales acaecidos desde el siglo xx han ido instalándose. Todo ello, unido al papel socializador de los medios de comunicación social y, hoy en día, más concretamente, de la cultura de pantalla, puesto que «la mediación de las pantallas para ejercer el mundo y formar comunidades, ha producido una forma de cultura en la que ver es creer y figurar es existin» (Becerra, 2005: 92-93). En la cultura de pantalla estarían incluidas, no solo las producciones de la industria cultural global y uniformadora, sino también las producciones propias, todas ellas con un común denominador: la mediación de la pantalla ${ }^{3}$. Las influencias que tienen niños y niñas, así como adolescentes, de los contenidos de estos dispositivos en la conformación de sus identidades está sorprendiendo por la velocidad de penetración, así como por la constante novedad que supone tener que adaptarse si queremos estar al día en contenidos y nuevas tecnologías.

Así, partimos de que actualmente los medios de socialización y la cultura de pantalla, -así como el grupo de iguales, en lo que supone un coadyuvante de los primeros-, se configuran como agentes de socialización de género mucho más importantes que antaño, por la influencia que éstos tienen a la hora de conformar las identidades de los y las adolescentes. Por su parte, la familia y la escuela pareciera que deben contrarrestar esa influencia, convirtiéndose, pues, el hecho educativo, en un proceso más complejo.

\section{Tabla I. Esquema resumen del proceso de socialización y sus agentes en las sociedades modernas}

\begin{tabular}{lcc}
\multicolumn{1}{c}{ TIPOS DE SOCIALIZACIÓN } & AGENTE SOCIALIZACIÓN & APRENDIZAJE \\
\hline PRIMARIA & Familia & $\begin{array}{c}\text { Normas básicas } \\
\text { (Deriva en valores afectivos) }\end{array}$ \\
\hline (ritmos vitales, lenguaje, etc.)
\end{tabular}

\section{CULTURA}

Fuente: elaboración propia.

Por tanto, partimos de la cultura de pantalla como predominante en la configuración de las identidades de género, hecho que ha sido ampliamente documentado desde los inicios de la televisión (Becerra, 2005; Chacón, 2015; Gallego, 2009; Lomas, 2002, 2005; Meyrowitz, 1992; entre otros/as). La influencia de los medios de comunicación, de la publicidad y de otros agentes similares es innegable a la hora de ofrecer visiones del mundo y arquetipos sociales y sexuales. Estos medios siguen reproduciendo la desigualdad sociocultural de las mujeres y siguen marcando una versión sutil y postmoderna de los arquetipos tradicionales de la virilidad y de la feminidad (Lomas, 2005: 259).

3 Incluimos aquí todos los dispositivos con pantalla y a través de los cuales las y los adolescentes se relacionan con el mundo: Smartphones, tablets, ordenadores, televisión, cine, etc. La mayoría de los contenidos son vistos y realizados a través de internet. 


\section{Objetivos e hipótesis de investigación}

El objetivo principal de este estudio es explorar cómo expresan y construyen los y las adolescentes de entornos rurales su identidad de género desde el punto de vista de la socialización diferencial de género. No tratamos de encontrar grandes respuestas ni generalidades, sino realizar una modesta aportación que sirva para la mejora del conocimiento de las relaciones que se establecen en y entre los diferentes agentes de socialización, así como para una mejora de la intervención socioeducativa en los centros de educación secundaria.

Asimismo, es nuestro interés aproximarnos al objeto de estudio para seguir haciéndonos preguntas, en un momento como el actual, en el que se están vislumbrando cambios sociales en las relaciones entre hombres y mujeres y sus consecuentes reacciones del sistema patriarcal.

Para lograr nuestro objetivo, se han tenido en cuenta diferentes cuestiones en relación con la adolescencia, como son:

- Las opiniones sobre el sexismo.

- Aspectos relevantes de la masculinidad.

- Las expectativas sobre su futuro.

- El consumo de medios de comunicación, especialmente la televisión y las redes sociales.

- Los usos del tiempo libre.

- Las personas que pueden suponer un referente para ellos y ellas.

Situado el tema de estudio, en un plano hipotético nuestra pretensión es avanzar en el análisis de aspectos principales que nos lleven a constatar realidades y/o consideraciones como las que a continuación se detallan:

1. Las identidades de género de chicos y chicas de primeros cursos de secundaria en relación con los estereotipos de género, las expectativas personales y la percepción de lo que la sociedad espera de ellos y ellas, siguen estando marcadas por identidades de género hegemónicas.

2. Las chicas son más tolerantes ante la diversidad de género que los chicos, ya que supone un mayor coste social para ellos.

3. Los agentes socializadores más influyentes en la adolescencia son los que tienen como vehículo las pantallas.

\section{Metodología y contextualización}

Para la realización de este análisis exploratorio se ha optado por una metodología cuantitativa, utilizándose como herramienta de recogida de información la encuesta. El cuestionario utilizado contiene una treintena de preguntas, que se distribuyen en los siguientes bloques temáticos: estructura familiar, percepción del sexismo de diferentes agentes, diversidad familiar y de género, formas de ocio, expectativas sobre su futuro, ideales de hombres y mujeres y uso y consumo de televisión y redes sociales. En detalle, el cuestionario incluye 12 preguntas dicotómicas, 4 de respuesta múltiple, 2 escalas Likert que se utilizan para medir aspectos relativos a la masculinidad y la feminidad, 8 preguntas abiertas que recogen información de diversa índole y 4 preguntas cerradas de elección única. Para la elaboración de este artículo se han 
seleccionado las preguntas más relevantes, utilizándose principalmente un análisis estadístico bivariado, siendo la variable sexo la que se ha cruzado con las demás variables analizadas, por ser clave en el planteamiento de la investigación.

Se ha realizado un muestreo por conglomerados de estudiantes de poblaciones rurales de la provincia de Albacete, seleccionando en primer lugar las áreas geográficas de análisis y posteriormente las aulas, encuestando a la totalidad del alumnado seleccionado.

La edad de la población objeto de estudio -alumnado de $1^{\circ}$ y $2^{\circ}$ de Educación Secundaria Obligatoria- es de 11 a 16 años, por lo que se consideró como mejor opción utilizar el cuestionario como una herramienta muy apropiada para que los sujetos puedan responder con mayor grado de sinceridad.

La muestra y los perfiles de la investigación quedan recogidos en la tabla II.

\section{Tabla II. Muestra de la encuesta (centro, edad, sexo y curso)}

\begin{tabular}{ll} 
Institutos de ESO & IES Cinxella: Chinchilla de Montearagón (17 km. de Albacete). \\
\cline { 2 - 2 } $\begin{array}{ll}\text { (comarcales) } \\
\text { Cursos }\end{array}$ & IES Alfonso Iniesta: Pozo Cañada (26,6 km. de Albacete). \\
\hline Edad & IES Pascual Serrano: Alpera (72 km. de Albacete). \\
\hline Muestra proyectada & De 11 a 16 años \\
\hline Muestra recogida & 4 grupos en cada IES. \\
\hline
\end{tabular}

Fuente: elaboración propia.

En la población objeto de estudio es algo superior el número de chicos $-51,7 \%$ - que de chicas $-48,3 \%$ - El $43 \%$ cursa $1^{\circ}$ de ESO y el resto se encuentra en $2^{\circ}$ curso. Sus edades oscilan entre los 11 y 16 años, siendo el 77,1\% de la muestra alumnado de 12 y 13 años. En cuanto a su nacionalidad, es predominantemente española, representando el $96,2 \%$ de las personas encuestadas. Por último, los datos de los estudios de padres y madres nos muestran que las madres poseen mayoritariamente estudios obligatorios de ESO o EGB (39\%), destacando además casi un 20\% de madres con estudios universitarios. Por su parte, un $45 \%$ de los padres tienen estudios obligatorios, mientras que algo más de un 12\% posee un título universitario.

La recogida de datos se llevó a cabo entre los meses de octubre y noviembre de 2016, en el marco del proyecto Creciendo en Igualdad del Instituto de la Mujer de Castilla-La Mancha ${ }^{4}$, cuyo objetivo es fomentar la igualdad de género y prevenir la violencia, utilizando una metodología participativa de impartición de sesiones de sensibilización en centros de educación secundaria de las zonas rurales de la Comunidad Autónoma de Castilla-La Mancha. Las sesiones en cada grupo tuvieron una duración de dos horas. El cuestionario autoadministrado fue cumplimentado por el alumnado antes de las sesiones, para evitar sesgos o condicionamientos a partir de informaciones recibidas sobre el tema.

El contexto donde se han realizado las encuestas son zonas rurales, que comprenden tres municipios de la provincia de Albacete: Chinchilla de Montearagón, con 4015 habitantes; Pozo Cañada, con 2895 habitantes y Alpera, con 2438 habitantes. Las tres poblaciones están situadas en el este de la provincia

4 http://institutomujer.castillalamancha.es/igualdad/programas/creciendo-en-igualdad. 
de Albacete, manteniendo bastante relación con la capital, puesto que Chinchilla y Pozo Cañada se encuentran situados a pocos kilómetros, siendo Alpera la más lejana. Las economías de los tres pueblos son diversas, ya que Chinchilla, al estar muy cerca de la capital, tiene un desarrollo más industrial que agrícola, disponiendo de varios polígonos industriales, además de parques eólicos. Por su parte, la economía de Pozo Cañada está basada en el sector del transporte y el agrícola. Por último, Alpera es una población eminentemente agrícola.

\section{Resultados}

\subsection{Conociendo a nuestro alumnado: Chicos y chicas ante el sexismo}

Diversos estudios han analizado el sexismo en la juventud española desde un punto de vista cuantitativo (Centro Reina Sofía sobre Adolescencia y Juventud y Fundación de Ayuda contra la Drogadicción, 2014, 2015; Díaz-Aguado y Carvajal, 2011). Estas investigaciones muestran un considerable grado de sexismo en nuestra juventud, y una gran influencia de lo que se ha denominado el espejismo de la igualdad (Valcárcel, 2013). Dichos estudios se han centrado en preguntar a jóvenes y adolescentes a partir de 14 años. Sin embargo, nuestro estudio abarca como universo poblacional el alumnado de $1^{\circ}$ y $2^{\circ}$ de ESO, es decir, preadolescentes de entre 11 y 16 años, siendo, como expone el apartado de metodología, el $77 \%$ de la muestra alumnado de 12 y 13 años.

Al preguntar la opinión del alumnado sobre si diferentes agentes -como las personas de su entorno, los medios de comunicación, así como ellos y ellas mismas- llevan a cabo un comportamiento machista (gráfico 1), destaca que son los medios de comunicación los valorados como más machistas, siendo en torno a un 70\% en el caso de la televisión y alrededor de un $65 \%$ en el caso de las revistas. Por otra parte, las chicas consideran en mayor medida que los chicos que el comportamiento de las profesoras es machista, mientras que los chicos consideran que el comportamiento de los profesores es más machista. Por último, tan solo un $4 \%$ de chicos considera que ellos mismos son machistas.

\section{Gráfico 1. Opinión sobre el grado de machismo de diferentes agentes o instituciones por sexo}

(\%)

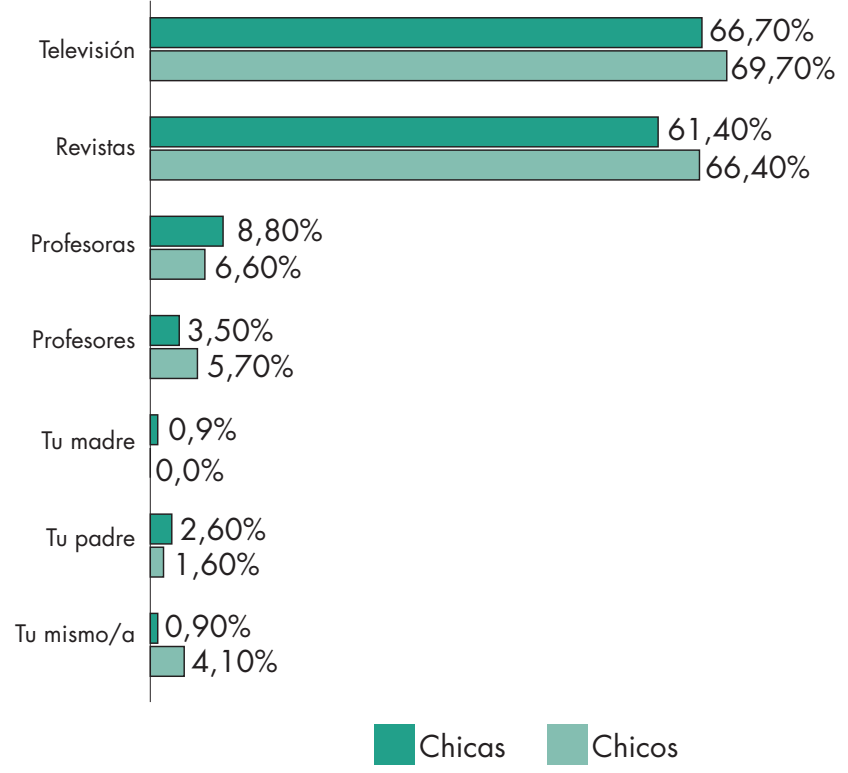

Fuente: elaboración propia. 
Otro aspecto que podemos tener en cuenta a la hora de analizar el sexismo son las opiniones sobre la segregación profesional por género. La mayoría de personas encuestadas considera que no existen trabajos que sean exclusivos de hombres o de mujeres. Pero destaca que más del 17\% de chicas piensa que sí existen trabajos para hombres y trabajos para mujeres, mientras que el porcentaje de chicos que piensan así es de casi un 12\%. Gran parte de los motivos que aducen para decir que hay trabajos diferenciados por sexo es la dureza de algunos empleos y la falta de capacidad de las mujeres para el desarrollo de estos. Vemos cómo los mandatos de género condicionan la visión que tienen, incluso las chicas, sobre los roles sociales a desempeñar, desde un punto de vista productivo.

\subsection{Aspectos relevantes de la masculinidad: emociones y diversidad de género}

En relación con los estereotipos de género y sus efectos en los comportamientos y expresiones hemos preguntado, entre otras cosas, si han llorado últimamente, ya que uno de los rasgos de la masculinidad hegemónica (Connell, 2015: 112) es la dureza emocional. Gran parte de los hombres no suelen mostrar sus sentimientos en público y muchos de ellos son incapaces incluso de llorar. Sobre esta cuestión hay que destacar un $17 \%$ de chicos que reconoce que ha llorado en la última semana, mientras que el porcentaje aumenta al preguntarles por el último mes, pasando a ser el 36\%. En el caso de las chicas, se dobla el valor, siendo el 44,7\% las que han llorado en la última semana y el 61,4\% las que reconocen haber llorado en el último mes.

Las chicas lloran más que los chicos, dado que la educación que reciben éstas está más vinculada a la demostración de sentimientos que la que reciben los chicos. En palabras de Carlos Lomas (2004: 25), «conviene educar a los chicos en una actitud crítica ante las conductas violentas y sexistas de algunos chicos, orientando a otras maneras de entender la masculinidad, porque los chicos también lloran». Así, que más de un tercio de los alumnos reconozca haber llorado en el último mes, parece un pequeño avance en este sentido.

Por otro lado, para conocer cómo valora la preadolescencia la diversidad de género en relación con las diferentes formas de familia, se solicitó que marcaran todos los tipos de convivencia que consideraran familias. Los resultados del gráfico 2 muestran que la opción más señalada es la estructura tradicional, formada por una pareja heterosexual con su descendencia, siendo señalada por el $87,7 \%$ de las chicas y por el 89,3\% de los chicos. Prácticamente el resto de los agrupamientos familiares, incluidos los tipos de relaciones homosexuales son consideradas familias más por las chicas que por los chicos. Los datos confirman la mayor permisividad de las chicas en relación con las formas de familia diversas desde el puntos de vista de género (Centro Reina Sofía sobre Adolescencia y Juventud y FAD, 2014).

Estos datos podrían corroborar la influencia de la masculinidad hegemónica, que tiene como una de sus características principales el cuestionamiento de la homosexualidad (Lomas, 2007), así como una tendencia a un retroceso de los chicos hacia posiciones más tradicionales (Compairé, 2011). 


\section{Gráfico 2. Valoración de los tipos de convivencia que consideran familias por sexo}

(\%)

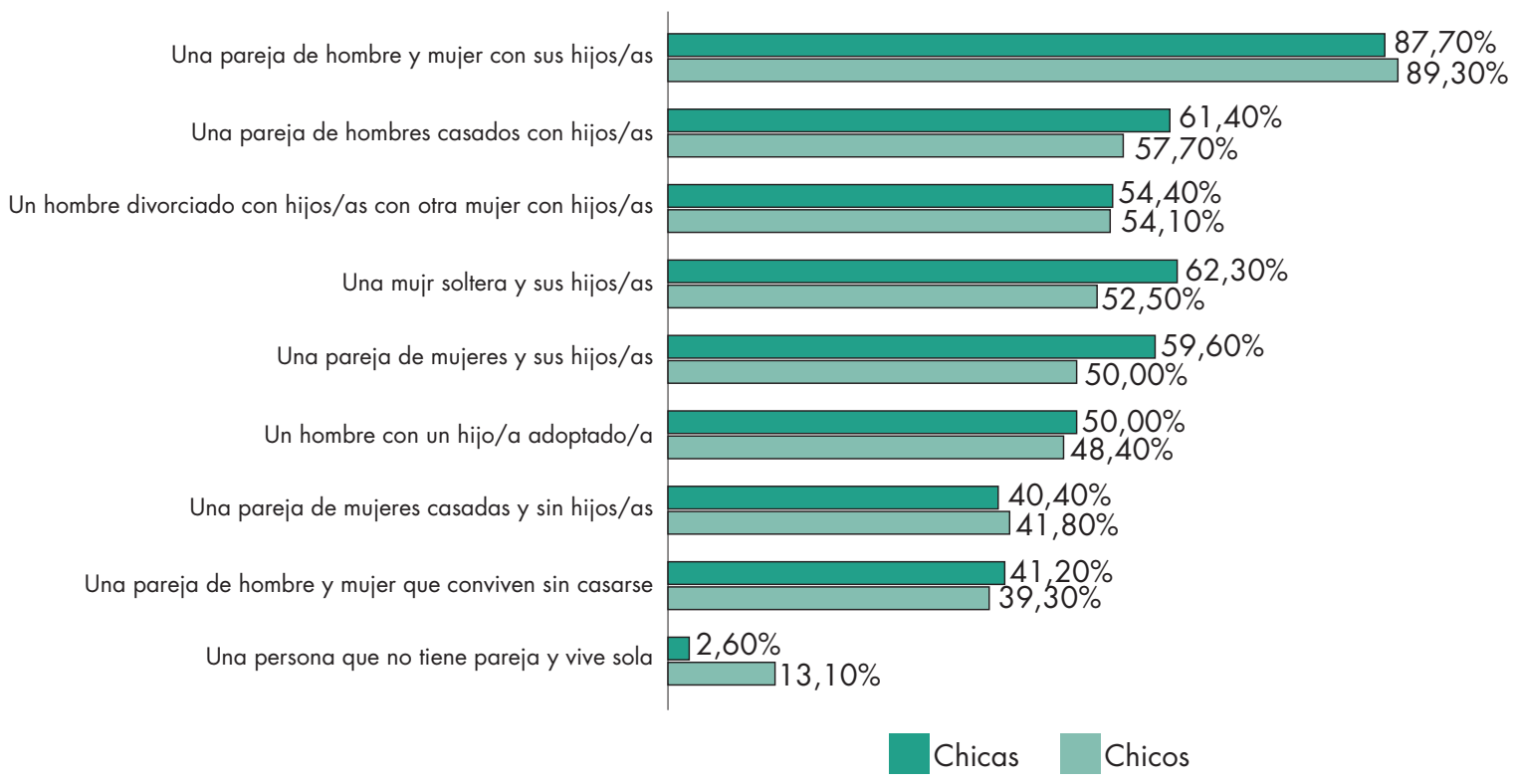

Fuente: elaboración propia.

Otra cuestión que consideramos relevante es conocer si las personas encuestadas se han podido llegar a sentir excluidas por tener pensamientos o comportamientos que supuestamente pertenezcan al otro sexo. En este caso, la mayoría no ha sentido ningún tipo de rechazo, pero es destacable que un 8,8\% de las chicas sí lo ha experimentado frente a un 5,7\% de chicos. Por otra parte, es preciso tener en cuenta que en ocasiones no son conscientes de si han sufrido algún tipo de rechazo por este motivo, ya que el porcentaje de no respuesta es muy significativo -alrededor de un $15 \%$-.

\subsection{Las expectativas sobre su futuro}

$\mathrm{Al}$ indagar en su futuro personal, los resultados muestran cómo los y las jóvenes se visualizan conviviendo en pareja y/o formando una familia. La mayoría (63\%) de chicos y de chicas considera que se casarán y que tendrán hijos. Sin embargo, casi una de cada cuatro chicas considera que vivirá en pareja, pero no tendrá hijos, mientras que el $21 \%$ de los chicos se imagina sin descendencia. Destaca el 9,3\% de chicas que considera que estarán en pareja sin estar casadas con hijos.

En cuanto a la profesión que creen que tendrán cuando sean mayores (gráfico 3), se vislumbran expectativas que reproducen el sesgo de género. Así, el 19\% de las chicas cree que será maestra y el 9,4\% médica. Son de destacar las profesiones más citadas por los chicos: militar (13,3\%), policía $(9,3 \%)$ y futbolista $(8,2 \%)$. 


\section{Gráfico 3. Expectativas profesionales por sexo}

$(\%)$

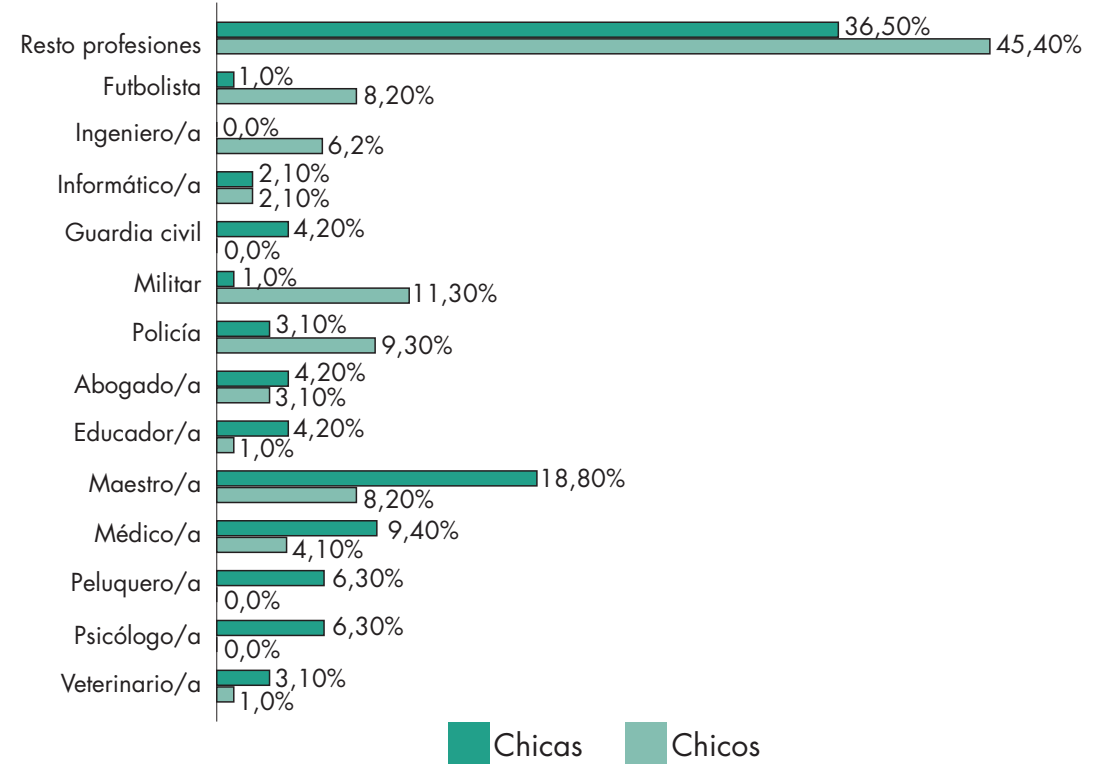

Fuente: elaboración propia.

Por otro lado, en relación con las expectativas de futuro que tiene la familia del alumnado, sabemos que suelen ser diferentes según el género (Fernández, 2003). Así, el 91,2\% de las chicas considera que su familia espera de ellas que estudie una carrera universitaria, mientras que el porcentaje de chicos se reduce al $83,6 \%$.

Siguiendo con las expectativas que el alumnado cree que tiene su familia en relación con la carrera que estudiarán, destacan las carreras del área de la salud, básicamente enfermería y medicina, pues la mitad de las chicas encuestadas cree que su familia desea que estudie carreras de esta área. Por otro lado, casi el $22 \%$ de las respuestas de los chicos indican que las expectativas están más relacionadas con carreras técnicas como ingeniería y arquitectura. Estos resultados confirman la segregación de género que tienen los diferentes estudios universitarios (MECD, 2016), y nos vuelven a poner en alerta sobre la importancia de las expectativas en relación con el futuro del alumnado. 


\section{Gráfico 4. Estudios que padres y madres quieren que estudie, según las personas encuestadas, por sexo (\%)}

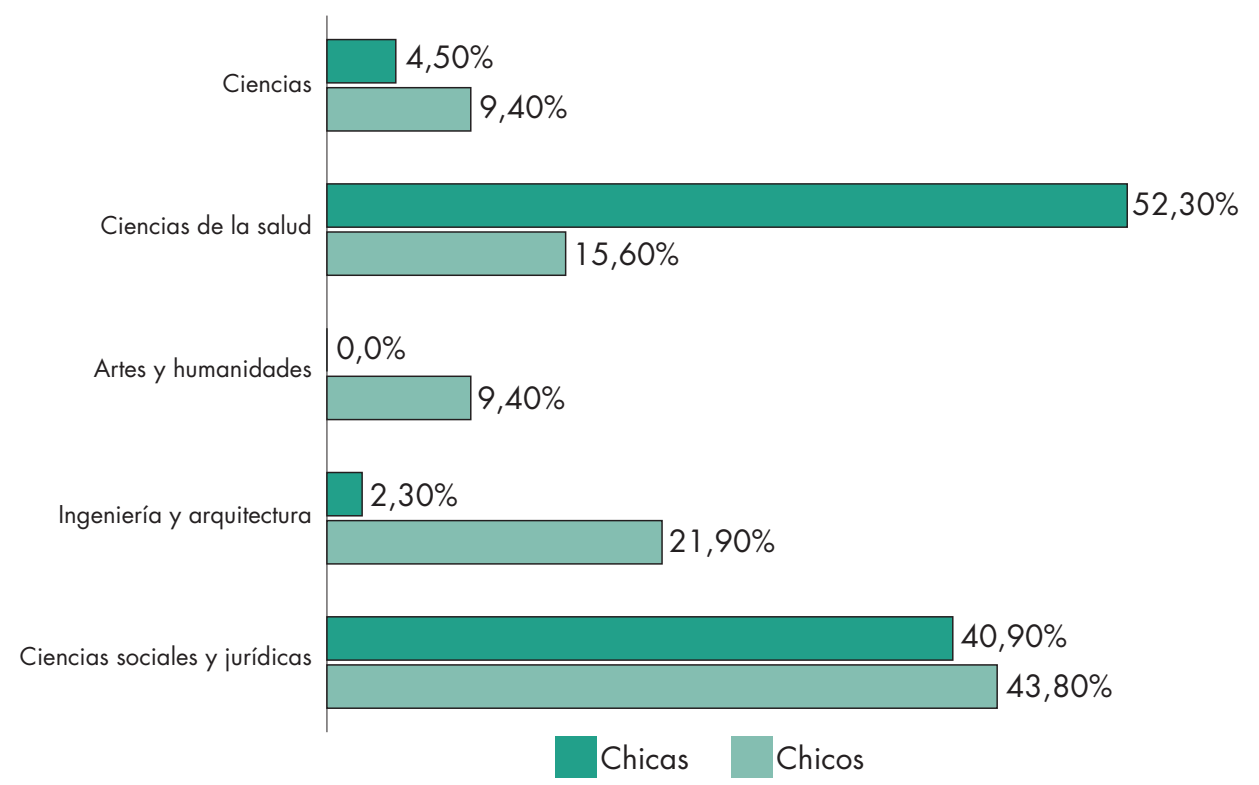

Fuente: elaboración propia.

\subsection{Televisión y redes sociales: ¿Qué consumen los y las adolescentes?}

Los medios de comunicación de masas poseen un discurso homogeneizador que intenta inducir a la construcción de la realidad social, elaborando los mensajes de estos medios a través de un poder simbólico universalizador del que raramente puede abstraerse la ciudadanía. Durante la adolescencia, los agentes de socialización como el grupo de iguales y los medios de comunicación, incluyendo las redes sociales online y los videojuegos, son muy influyentes. A través de la cultura de masas, entre otros medios, se construyen y difunden los arquetipos de lo femenino y de lo masculino, consagrando la desigualdad de las mujeres en los ámbitos de lo íntimo y de lo público y se impone a las personas una determinada forma de entender el mundo y las relaciones entre hombres y mujeres (Lomas, 2002).

En nuestra investigación se preguntó sobre los programas de televisión favoritos (gráfico 5), resultando sorprendente que el programa preferido por chicos y chicas sea la serie La que se avecina. Casi el $60 \%$ de los chicos y más de la mitad de las chicas tiene como programa favorito esta serie, cuyo formato, personajes y configuración de las relaciones de pareja «contribuyen al fortalecimiento de ciertos patrones sexistas, no solo a través de la imagen, sino también a través de la palabra» (Folgueras, 2011: 32). Esta serie de la productora Mediaset nació en 2007 como secuela de otra serie titulada Aquí no hay quien viva. La que se avecina fue inicialmente catalogada para mayores de 7 años, pasando después a ser clasificada para mayores de $12 \mathrm{y}$, finalmente, para mayores de 16 años.

Destaca, por otro lado, que las chicas ven más series que los chicos y los chicos más programas deportivos que aquellas. Además, el programa Mujeres y hombres y viceversa es más visto por chicas que por chicos. 


\section{Gráfico 5. Programa favorito por sexo}

(\%)

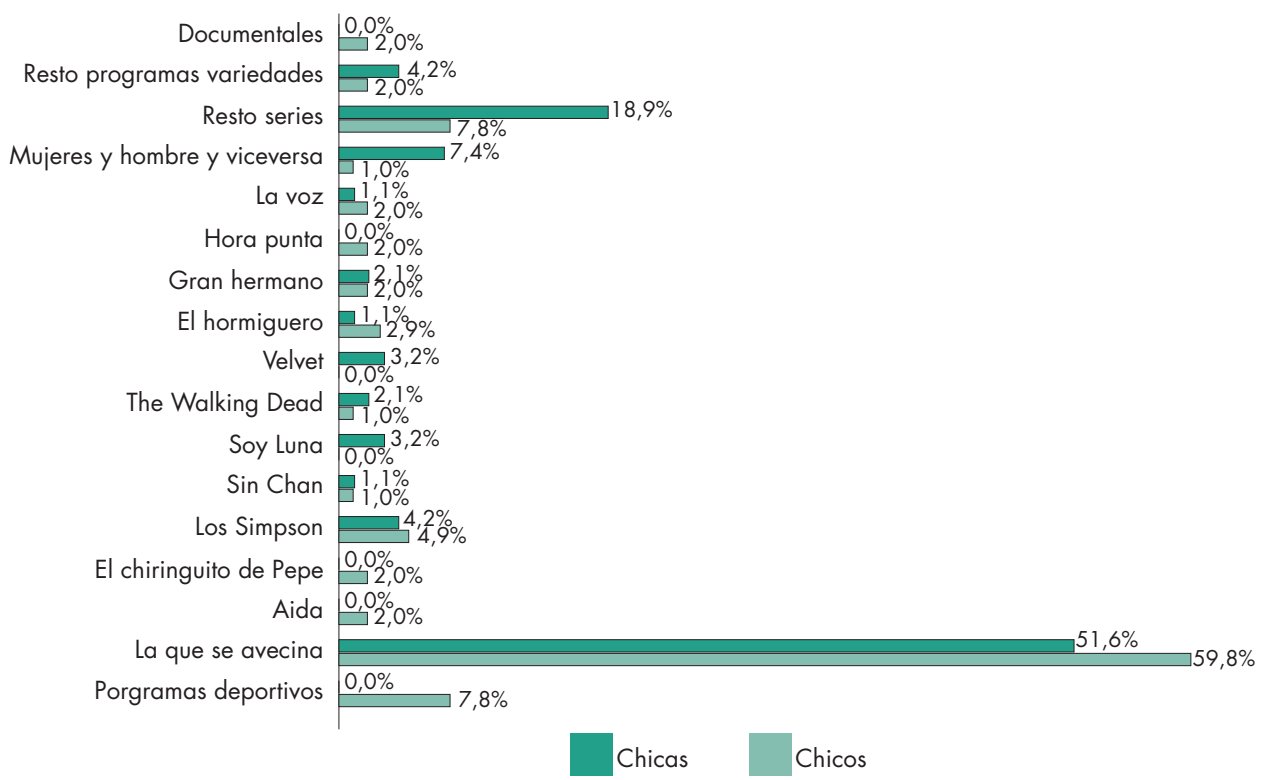

Fuente: elaboración propia.

En cuanto a las redes sociales ${ }^{5}$, éstas suponen un medio a través del cual las personas adolescentes se relacionan sin problema. Las identidades adolescentes de este comienzo de siglo están influidas en parte por estas redes sociales y sus contenidos, por las identidades virtuales que se crean en estos espacios o perfiles y por las relaciones que establecen entre sus iguales. En las últimas décadas, Internet y las nuevas formas de comunicación están suponiendo una nueva forma de entender el mundo, produciéndose además grandes diferencias generacionales que son cada vez más pronunciadas gracias a estos medios.

La cultura de pantalla es el medio a través del cual las personas adolescentes participan de una cultura en la que «ver es creer y figurar es existir» (Becerra, 2005: 92-93). Así, la imagen proyectada se torna una de las cosas más importantes en la adolescencia. No solo la imagen proyectada, sino también la que devuelven las redes con los likes, los comentarios, el número de personas seguidoras, etc. Todo ello influye de manera determinante en la construcción de la identidad adolescente. Si la realidad se construye socialmente y las identidades también, ambos son construidos por la interacción y la relación dialógica entre individuo y sociedad, a través de las relaciones reales y virtuales entre la persona y el entorno, puesto que:

"Un entorno ya no es exclusivamente offline, sino que se suma también la realidad online de cada persona. Esto implica que el uso que niños, niñas y adolescentes hacen de las nuevas tecnologías tiene consecuencias para sí mismos, pero además transcienden el plano interpersonal y afectan también a toda la sociedad en el modo de entender, interpretar la realidad y las relaciones entre personas. La construcción de nuevos significados compartidos se enmarca asi dentro de una lógica de comportamientos que son paulatinamente institucionalizados a partir de las exigencias normativas a los agentes sociales». (Save The Children, 2010: 17).

\footnotetext{
5 En España, el acceso a estas plataformas está regulado en el art. 13 del Real Decreto 1720/2007, de 21 de diciembre, por el que se aprueba el Reglamento de desarrollo de la Ley Orgánica 15/1999, de 13 de diciembre, de protección de datos de carácter personal, que establece que "podrá procederse al tratamiento de los datos de los mayores de catorce años con su consentimiento, salvo en aquellos casos en los que la Ley exija para su prestación la asistencia de los titulares de la patria potestad o tutela. En el caso de los menores de 14 años se requerirá el consentimiento de los padres o tutores».
} 
En relación con el uso de estas redes, nuestra investigación muestra que más del $88 \%$ de las alumnas encuestadas tiene presencia en las redes sociales, siendo algo más del $86 \%$ los chicos que disponen de ellas. Por edades, son las chicas de 13 años las que más utilizan las redes sociales (50,5\%).

La red social más utilizada por chicos y chicas es Instagram, como muestra el gráfico 6, con un 37\% y un $39 \%$ respectivamente, seguida por Whatsapp. Tras estas dos redes, Snapchat la utiliza un $20 \%$ de chicas y solo un $12 \%$ de chicos. Redes sociales como Facebook y Twitter son más utilizadas por chicos que por chicas.

\section{Gráfico 6. Redes sociales utilizadas por el alumnado por sexo y total}

(\%)

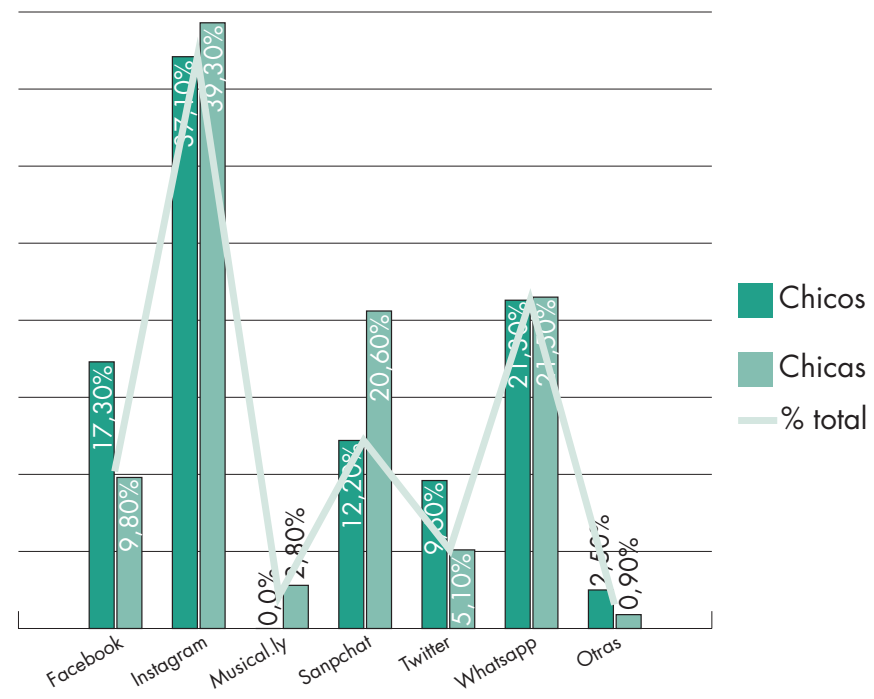

Fuente: elaboración propia.

\subsection{Tiempo libre: grupo de iguales, deporte y videojuegos}

Si la identidad se forma por procesos sociales y una vez formada es mantenida, modificada o reformada por las relaciones sociales (Berger y Luckmann, 2003: 214), es en la adolescencia cuando el grupo de iguales se configura como uno de los agentes más significativos.

Al preguntar por el grupo de iguales, la mayoría del alumnado contesta que sus amistades más cercanas son chicos y chicas por igual, siendo el porcentaje en el caso de las chicas el $72 \%$ y de los chicos el $67 \%$. Sin embargo, es revelador que alrededor de una cuarta parte de adolescentes considere que sus amistades más cercanas son sobre todo personas de su mismo sexo.

Por otro lado, el gráfico 7 muestra datos sobre los usos del tiempo libre, revelando que los chicos pasan mayoritariamente su tiempo libre practicando algún deporte, sobre todo fútbol -casi un 36\%-, lo que contrasta con los datos de las chicas que confirman que las mujeres practican menos deporte que los hombres, hecho que es consecuencia de la socialización diferencial de género. El deporte ha sido tradicionalmente un sector de dominio masculino y, más recientemente, «el deporte se ha convertido en lo que define principalmente la masculinidad dentro de la cultura de masas» (Connell, 2015: 87), y la igualdad de género aquí se ve entorpecida por las interpretaciones sociales relativas a la feminidad y la masculinidad. El índice de igualdad de género del Instituto Europeo para la Igualdad de 
Género indica que, mientras que las mujeres dedican más tiempo, en comparación con los hombres, al cuidado de otras personas, participan menos en otras actividades sociales, como las deportivas, las culturales o las de ocio (EIGE, n.d.). No obstante, un 21\% de las chicas suele hacer deporte en su tiempo libre.

Por otra parte, hay que destacar que casi un tercio de las chicas dedica la mayor parte del tiempo libre a estar con amistades.

\section{Gráfico 7. Actividades que suelen hacer en su tiempo libre por sexo}

(\%)

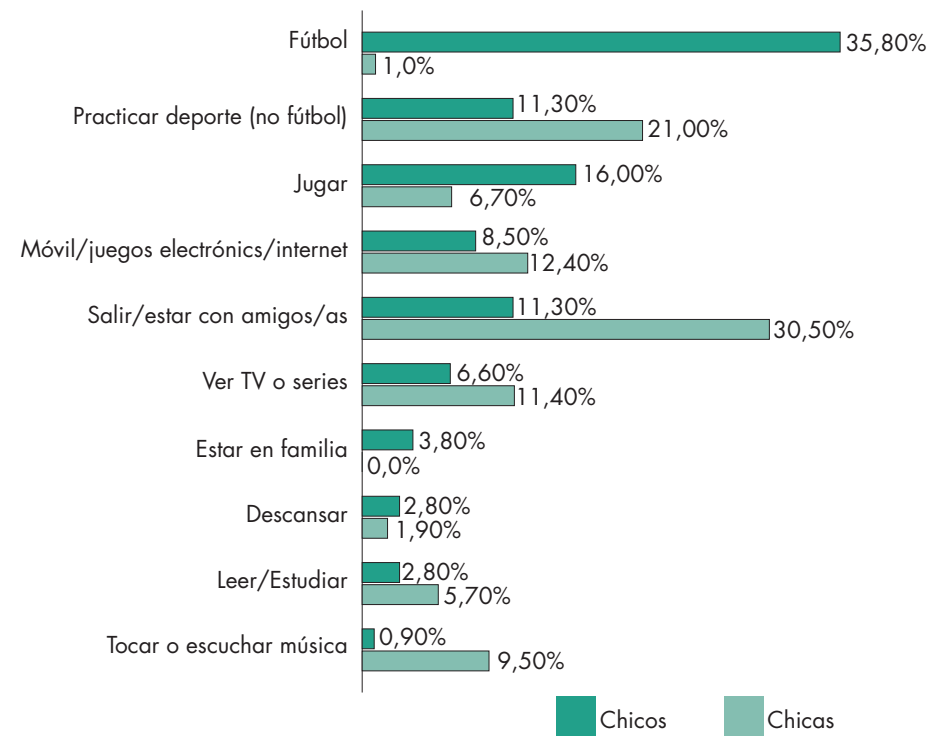

Fuente: elaboración propia.

Cuando la pregunta realizada es concretamente si practican algún deporte, se pone de manifiesto que ambos sexos lo realizan con frecuencia, aunque con mayor asiduidad los chicos que las chicas. Casi un $87 \%$ de los chicos de la muestra realiza algún deporte de forma habitual, mientras que el porcentaje de chicas supone casi el $70 \%$.

También se preguntó por las actividades que realizan en el tiempo libre del centro educativo, ya que el patio (y la escuela) suponen un mercado simbólico, en el que la moneda de cambio es el prestigio que se conquista imitando los estereotipos de la masculinidad dominante y el ejercicio del poder y la opresión contra las chicas y también contra los chicos que no tengan el capital simbólico que se obtiene a través de la adhesión inquebrantable a los arquetipos viriles de la masculinidad tradicional (Bourdieu, 1982).

Así, el gráfico 8 expone que, durante el recreo, el $86 \%$ de las chicas está con sus amistades, mientras que los chicos reparten su tiempo entre estar con amistades (44\%), hacer deporte $(30 \%)$ y jugar $(15,7 \%)$. 


\section{Gráfico 8. Actividades que suelen realizar en el recreo del instituto por sexo}

(\%)

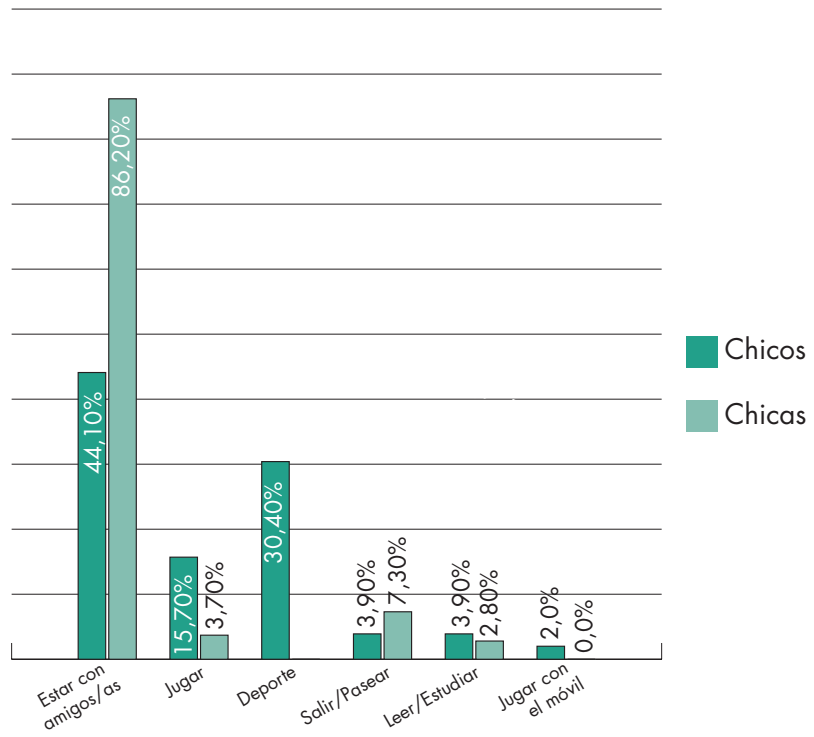

Fuente: elaboración propia.

Por último, los videojuegos constituyen una forma de ocio habitual para los chicos, ya que casi un $92 \%$ de ellos afirma que les gusta, mientras que el porcentaje se reduce a algo menos de la mitad $(46 \%)$ en el caso de las chicas.

En cuanto a los videojuegos favoritos (Tabla III), entre los chicos el más exitoso es el juego de fútbol FIFA (34,7\%), seguido de juegos de acción y guerra, como Call of Duty (28,7\%) y Grand Theft Auto (16,8\%). Este último videojuego ha sido considerado uno de los más violentos y sexistas del mercado. En este aspecto existe, al igual que con la programación de la televisión, una clasificación de los videojuegos recomendando las edades a partir de las cuales se debería jugar. Así, el sistema PEGI (Pan European Game Information) no recomienda estos dos últimos juegos para menores de 18 años.

Por su parte, menos de la mitad de las chicas reconoce que le gustan los videojuegos. Sin embargo, de este porcentaje, sus videojuegos favoritos son Call of Duty (22,6\%) y Mario Karts (19,4\%).

\section{Tabla III. Videojuego favorito (\%)}

\begin{tabular}{lll} 
& CHICOS & CHICAS \\
\hline Animal Crossing & 0 & 6,5 \\
\hline Call of Duty & 28,7 & 22,6 \\
\hline Clash Royale & 11,8 & 6,4 \\
\hline FIFA & 34,7 & 9,7 \\
\hline GTA & 16,8 & 9,7 \\
\hline Just dance & 0 & 6,5 \\
\hline Mario Karts & 0 & 19,4 \\
\hline Otros & 8 & 19,2 \\
\hline & 100 & 100 \\
\hline
\end{tabular}

Fuente: elaboración propia. 


\subsection{Referentes para la adolescencia}

Para indagar en los referentes que tienen estos/as jóvenes, se ha preguntado por su mujer y hombre ideales, así como por las cualidades de estas personas. Las preguntas se plantearon abiertas, por lo que las respuestas podían incluir desde personas de su entorno a personas famosas o relevantes, así como cualidades de todo tipo.

El gráfico 9 muestra cómo el 41,2\% de las chicas ven en su madre el referente femenino por excelencia. Por otro lado, mujeres famosas y otras mujeres de su familia, suponen cada grupo un $20 \%$. Estos datos avalan el hecho de la importancia de la familia en el proceso de socialización de las niñas (Espinosa, 2007). En el caso de los varones, sus valoraciones se decantan en primera opción por las mujeres famosas $(36 \%)$, seguidas de las amigas (28\%), quedando la figura materna en tercera posición $(21,3 \%)$.

\section{Gráfico 9. Mujer ideal por sexo}

(\%)

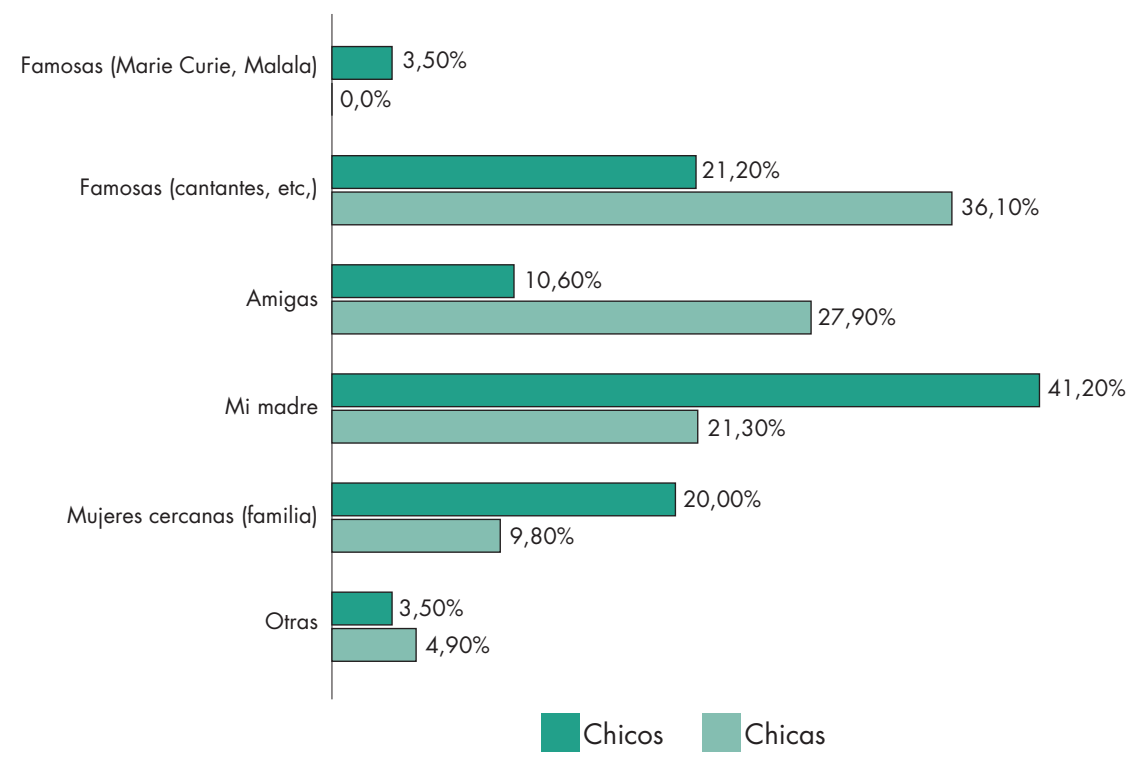

Fuente: elaboración propia.

La descripción de las cualidades de la mujer ideal que hacen chicos y chicas son cualitativamente diferentes. El gráfico 10 muestra cómo, en el caso de las chicas, priman características como la amabilidad, la afectividad, la humildad y la generosidad con un $21 \%$ en total. Seguidas estas cualidades por las formadas por el bloque relacionado con valentía, atrevimiento y aventura (14,2\%). En tercer lugar, se encuentra el bloque que hace referencia a la bondad de la persona con adjetivos señalados como: buena, comprensiva y cariñosa $(9,3 \%)$. Por tanto, podemos afirmar que casi un tercio de las chicas valora a su mujer ideal como una mujer buena, afectiva, cariñosa y otras cualidades similares.

Por otro lado, los varones sitúan las características físicas por encima de los rasgos de personalidad. Un $42 \%$ de los chicos define a su mujer ideal como guapa (22,1\%) y otras cualidades relacionadas con el aspecto físico. 


\section{Gráfico 10. Descripción de la mujer ideal por sexo}

(\%)

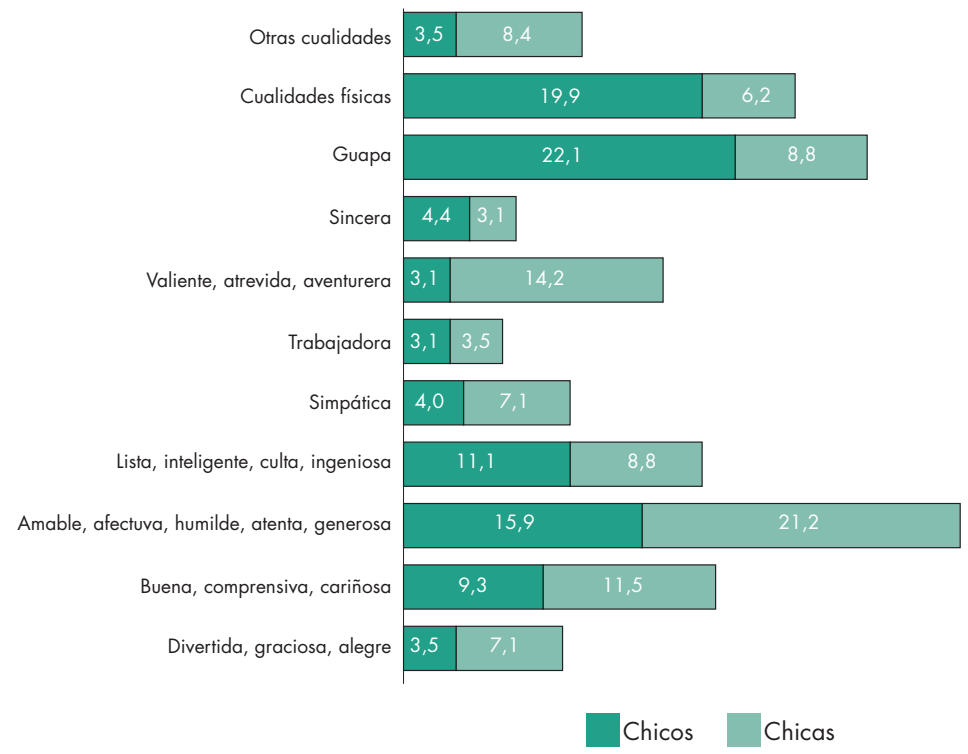

Fuente: elaboración propia.

En cuanto al hombre ideal (gráfico 11), también hay diferencias significativas entre chicos y chicas. Destaca que un tercio de estas últimas afirma que su hombre ideal es su padre. Tras este, identifican a hombres famosos como actores o cantantes, con un 20,5\%. En tercer lugar, las chicas tienen como hombre ideal a alguien de su entorno cercano.

Por otro lado, casi un tercio de los chicos refiere que el hombre ideal es alguien de sus amistades, lo que refuerza la idea de la gran influencia que ejerce el grupo de iguales a esta edad (Arenas, 1996; Padrós, 2012; Rodríguez, 2007; Sabuco et al., 2013). Uno de cada cuatro chicos opina que es su padre el hombre ideal. Por otro lado, hay que destacar que el $23 \%$ afirma que su hombre ideal es un famoso, identificando de entre estos más del 15\% que nombra a un futbolista. Por último, subrayar una minoría de casos $(6,4 \%)$ de chicos que responden «no soy homosexual», reforzando con ello que no son capaces de identificar a un hombre ideal si no es relacionándolo con la orientación del deseo, marcando nuevamente el influjo de la masculinidad hegemónica en la conformación de las identidades masculinas. 


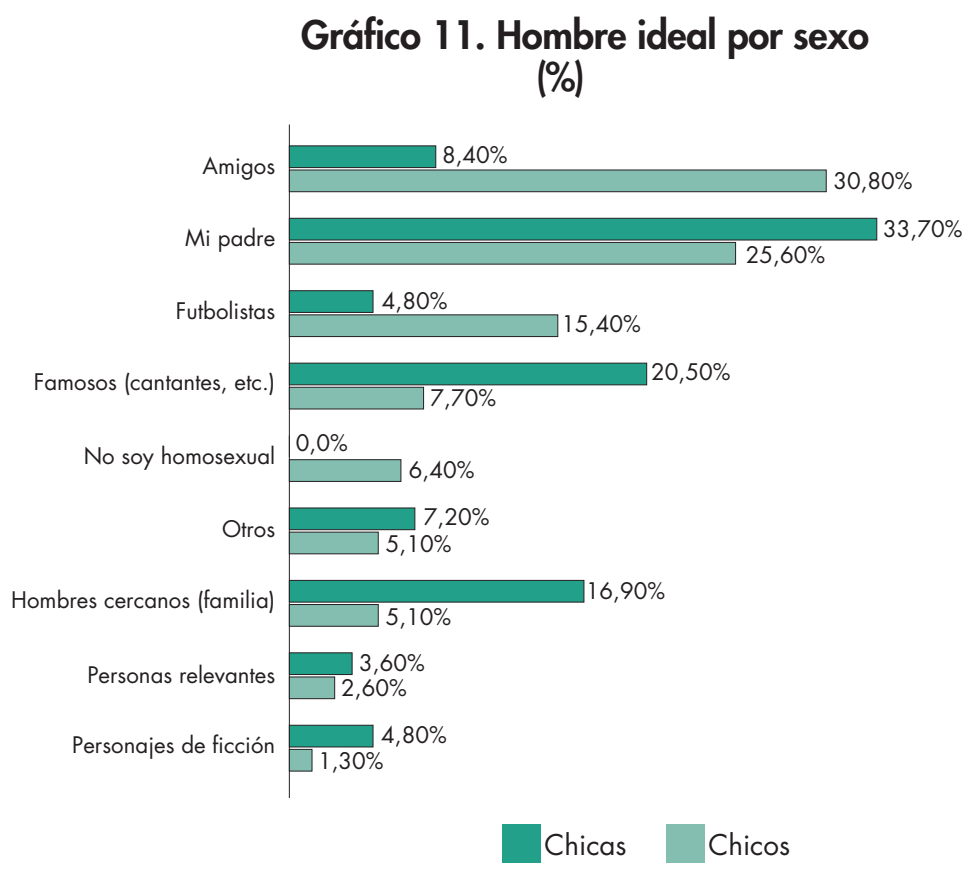

Fuente: elaboración propia.

A la hora de describir al hombre ideal, el gráfico 12 muestra que lo que más valoran las chicas son cualidades como amable, afectuoso, etc. Estas características, junto con la bondad, la comprensión y ser cariñoso, suponen casi un $40 \%$. Tras estas, la que más destaca es la belleza.

Por su parte, los chicos valoran en su hombre ideal características como la amabilidad, la humildad y la generosidad (20,5\%), seguido de cualidades físicas. Es de subrayar que los chicos describen a su hombre ideal en segundo lugar por cualidades físicas que, incluyendo la belleza, suponen casi un $24 \%$. Después, las características que más repiten son la valentía, el atrevimiento, la fortaleza o ser deportista $(12,5 \%)$.

Las diferencias de valoración de chicos y chicas en relación con la mujer y el hombre ideales muestran la socialización diferencial de género y los referentes o modelos que pueden influir en la conformación de las identidades de género adolescentes. 


\section{Gráfico 12. Descripción del hombre ideal por sexo}

(\%)

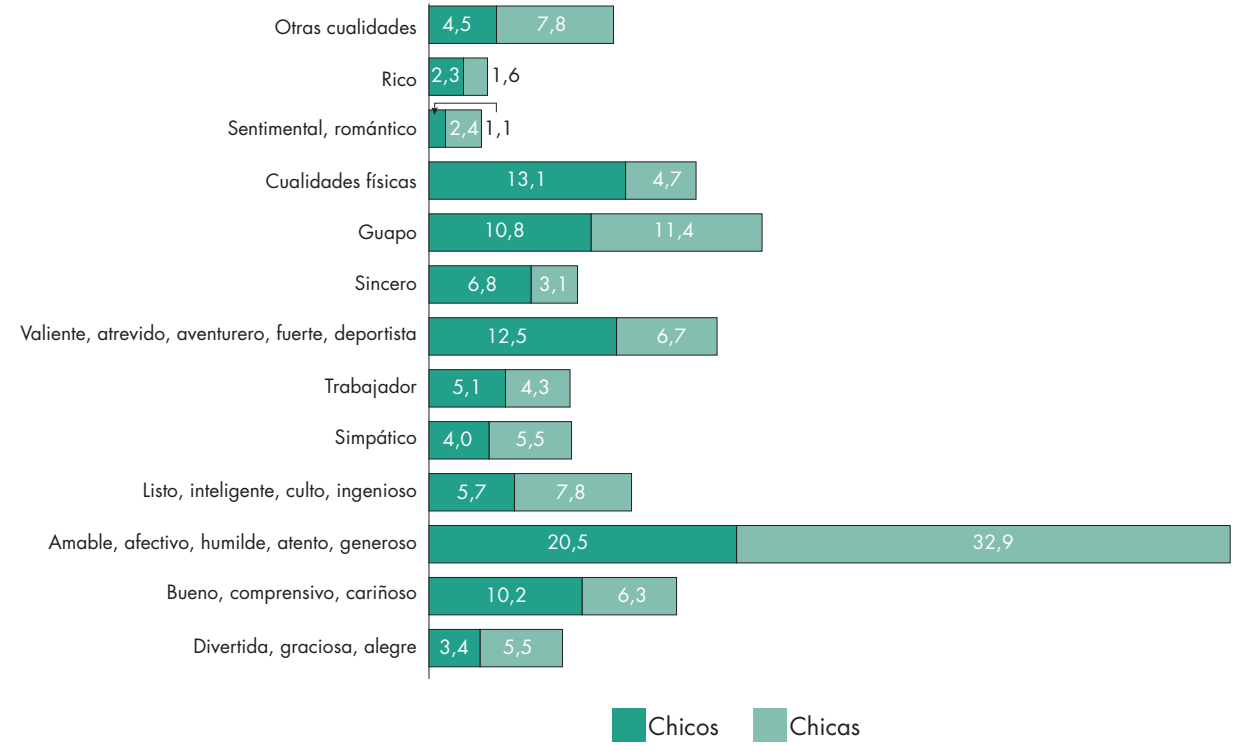

Fuente: elaboración propia.

\section{Conclusiones y propuestas de trabajo desde el ámbito escolar}

A partir de la socialización diferencial de género como paradigma teórico, se ha puesto el foco en agentes y aspectos que nos parecen cruciales a la hora de abordar la formación y expresión de las identidades masculinas y femeninas, como son el grupo de iguales, los medios de comunicación, las redes sociales, las expectativas, los referentes adultos y el tiempo libre.

En primer lugar, constatamos la primera hipótesis, pues las identidades de género de chicos y chicas de zonas rurales, de primeros cursos de secundaria, en relación con los estereotipos de género, las expectativas personales y la percepción de lo que la sociedad espera de ellos y ellas, siguen estando marcadas por las identidades de género hegemónicas. Pese a ello, consideramos pequeños avances, como por ejemplo que uno de cada tres chicos manifieste que ha llorado en el último mes.

En segundo lugar, la investigación pone en evidencia que las chicas son más abiertas que los chicos en relación con la diversidad de género, mostrándose ellos algo más tradicionales que ellas, lo cual se muestra en línea con la idea de que la homofobia supone una de las características de la masculinidad hegemónica, confirmando así nuestra segunda hipótesis.

En cuanto a la influencia de los diferentes agentes de socialización analizados, se confirma la tercera hipótesis para los chicos, pero no para las chicas, pues hemos advertido que tanto la cultura de pantalla como el grupo de iguales influyen más en ellos que en ellas. Por otro lado, una de las cuestiones que más nos ha llamado la atención es que la familia (madre y padre) sigue siendo un referente para las chicas, pero no tanto para los chicos. Creemos que esto hay que tenerlo en consideración en nuestra acción educativa desde la escuela y la familia.

Desde los centros escolares disponemos de un tiempo y un espacio propicio para trabajar, dentro del ámbito de la coeducación, desde todos los niveles del sistema educativo, desde los 0 años. Debemos educar a los niños y a los chicos en la empatía y en el valor de los cuidados, desde una educación emocional que les ha sido vedada desde muchos ámbitos de socialización. 
Por último, es indispensable facilitar aprendizajes y metodologías que tengan como objetivo el desarrollo de la capacidad de análisis y del espíritu crítico ante los contenidos de los medios de comunicación más influyentes en la infancia y la adolescencia. Puesto que las redes sociales y otros medios vinieron para quedarse, la familia y la escuela, como agentes de socialización primaria, tenemos la responsabilidad de guiar a niños y niñas y dotarles de los recursos necesarios para que de forma autónoma puedan enfrentarse a los retos que les deparará el futuro.

Para finalizar, dejamos abiertas las líneas de trabajo para profundizar en la influencia de los agentes de socialización en las identidades de género adolescentes, donde habrá que incidir en futuros análisis cualitativos que complementen y desarrollen este trabajo exploratorio.

\section{Referencias bibliográficas}

Arenas, Gloria (1996): “La cara oculta de la escuela” en Gloria Arenas: Triunfantes perdedoras. Málaga: Universidad de Málaga.

Becerra Villegas, Jesús (2005): “Culturas de Pantalla y Violencia Simbólica”. Quórum Académico, 2 (2), 89103.

Berger, Peter L. y Luckmann, Thomas (2003). La construcción social de la realidad. Buenos Aires: Amorrortu.

Bourdieu, Pierre y Passeron, Jean-Claude (1996). La reproducción. Elementos para una teoría del sistema de enseñanqa. México D. F.: Editorial Laia.

Centro Reina Sofía sobre Adolescencia y Juventud y Fundación de Ayuda contra la Drogadicción (2014). Jóvenes y género. El estado de la cuestión. Madrid: FAD.

Centro Reina Sofía sobre Adolescencia y Juventud y Fundación de Ayuda contra la Drogadicción (2015). Fuerte como papá, sensible como mamá. Madrid: FAD.

Chacón, Pedro (2015): "La publicidad sexista en la actualidad" en Ministerio de Educación, Cultura y Deporte: Eros y anteros, visiones sobre la sexualidad femenina. Madrid: MECD.

Connell, Raewyn (2015). Masculinidades. México D.F.: Universidad Nacional Autónoma de México.

Compairé, Juanjo (coord.) (2011). Chicos y chicas en relación. Materiales de coeducación y masculinidades para la Educación Secundaria. Barcelona: Icaria.

De Beauvoir, Simone (1998). El segundo sexo. Vol. I. Los hechos y los mitos. Madrid: Cátedra.

De Miguel, Ana (2015). Neoliberalismo sexual. El mito de la libre elección. Madrid: Cátedra.

Díaz-Aguado, $\mathrm{M}^{\mathrm{a}}$ José y Carvajal, $\mathrm{M}^{\mathrm{a}}$ Isabel (dirs.) (2011). Igualdad y prevención de la violencia de género en la adolescencia. Madrid: Ministerio de Sanidad, Política Social e Igualdad.

EIGE (n.d.). La igualdad de género en el deporte. Instituto Europeo para la Igualdad de Género. DOI: http://eige.europa.eu/sites/default/files/documents/mh0215937esn.pdf.

Espinosa, Ángeles (2007). La construcción del género desde el ámbito educativo: una estrategia preventiva. País Vasco: Emakunde-Nahiko.

Fernández, Francisco (2003). Sociología de la educación. Madrid: Pearson. 
Folgueras, Paloma (2011). Series de televisión y jóvenes: estereotipos y relaciones de pareja. El caso de "La que se avecina”. Trabajo Fin de Master. Master en Estudios Feministas Universidad Complutense de Madrid. DOI: https://eprints.ucm.es/13899/1/TFM_Paloma_Folgueras.pdf

Gallego, Joana (2009). La construcción del género a través de la publicidad (en línea). http://www3.udg. $\mathrm{edu} /$ publicacions/vell/electroniques/congenere/ponencies/01_construc cion_genero.pdf, consultado el 11 de abril de 2016.

Lomas, Carlos (2002): "El aprendizaje de las identidades femeninas y masculinas en la cultura de masas" en Ana González y Carlos Lomas (coords.): Mujer y educación. Educar para la igualdad, educar desde la diferencia. Barcelona: Graó.

Lomas, Carlos (2003). ¿Todos los hombres son iguales? Identidades masculinas y cambios sociales. Barcelona: Paidós Contextos.

Lomas, Carlos (comp.) (2004). Los chicos también lloran. Identidades masculinas, igualdad entre los sexos y coeducación. Barcelona: Paidós.

Lomas, Carlos (2005): “¿El otoño del patriarcado? El aprendizaje de la masculinidad y de la feminidad en la cultura de masas y la igualdad entre hombres y mujeres”. Cuadernos de trabajo social, 18, 259-278.

Lomas, Carlos (2007): “¿La escuela es un infierno? Violencia escolar y construcción cultural de la masculinidad”. Rev. De Educación, 342, 83-101.

MECD (2016). Datos y cifras del sistema universitario español. Curso 2016-2016. DOI: http://www. mecd.gob.es/dms/mecd/servicios-al-ciudadano-mecd/estadisticas/educacion/universitaria/datoscifras/datos-y-cifras-SUE-2015-16-web-.pdf.

Meyrowitz, Joshua (1992). No Sense of Place. University of New Hamsphire: Oxford University Press

Padrós, María (2012): "Modelos de atractivo masculinos en la adolescencia". Masculinities and Social Change, $1(2), 165-183$.

Rocha, Tania Esmeralda (2009): "Desarrollo de la identidad de género desde una perspectiva psico-sociocultural: un recorrido conceptual”. Interamerican Journal of Psychology, 43 (2), 250-259.

Rodríguez, Ma del Carmen (2007): "Identidad masculina y contexto escolar: notas para un debate". Rev. De Educación, 342, 397-418.

Ruiz Repullo, Carmen (2014). Los modelos de atracción en la adolescencia: ¿el triunfo de las identidades hegemónicas? V Congreso Universitario Internacional Investigación y Género. Sevilla.

Sabuco, Assumpta; Sala, Arianna; Santana, Rita y Rebollo, Ma Ángeles (2013): "Discursos de niños varones sobre la masculinidad en contextos escolares. Un estudio piloto". Rev. De curriculum y formación del profesorado,17 (1), 141-157.

Save The Children (2010). La tecnología en la preadolescencia y adolescencia: usos, riesgos y propuestas desde los y las protagonistas. DOI: http://www.de0a18.net/pdf/doc_tecno_estudio_riesgos.pdf.

Subirats, Marina y Tomé, Amparo (2007). Balones fuera. Barcelona: Octaedro. 
Taberner, José (2009). Sociología y educación. El sistema educativo en sociedades modernas. Funciones, cambios y confictos. Madrid: Tecnos.

Valcárcel, Amelia (2013). Feminismo en el mundo global. Madrid: Cátedra.

\section{Notas biográficas}

Gema Jiménez Tostón es profesora asociada de Sociología en la Facultad de Educación de la UCLM desde 2009 y trabaja como socióloga y agente de igualdad en el Ayuntamiento de Albacete desde 1997. Sus líneas principales de trabajo y de investigación son la educación y los estudios de género, habiendo impartido diversas conferencias y ponencias, así como distintas publicaciones sobre dichos temas. Ha sido formadora en múltiples talleres de coeducación e igualdad y prevención de la violencia de género con alumnado de primaria y secundaria, así como con profesorado y familias.

Francisco Javier Aroca Cifuentes es sociólogo y máster en Problemas sociales. Su experiencia profesional se ha centrado en la investigación social y de mercados para diferentes entidades y empresas. Desde 2003 ha participado en numerosos estudios y ha coordinado diversas investigaciones en el ámbito de Castilla-La Mancha. Sus principales líneas de investigación son: inmigración, género, exclusión social, administración local, evaluación de servicios y necesidades formativas; habiendo realizado ponencias sobre dichos temas. Además, es profesor tutor de la asignatura Sociología de la diversidad en el centro asociado de Cartagena (UNED). 